\title{
Two Phase Flow and Thermal Physics of Nanofluids: Understanding the Fundamentals, Mechanisms and Challenges
}

\author{
Lixin Cheng ${ }^{1,2}$ and Guodong Xia ${ }^{1}$ \\ ${ }^{1}$ College of Environmental and Energy Engineering, Beijing University of Technology \\ Beijing, China \\ ${ }^{2}$ Department of Engineering and Mathematics, Sheffield Hallam University \\ City Campus, Howard Street, Sheffield S1 1WB, UK \\ 1.cheng@shu.ac.uk; xgd@bjut.edu.cn
}

\begin{abstract}
This keynote lecture presents a comprehensive review of the state-of-the-art research on nanofluid two phase flow and thermal physics. First, studies of the physical properties of nanofluids are summarized. Then, analysis of the available experimental studies on nucleate boiling and critical heat flux (CHF) is presented. Next, flow boiling and two phase flow of nanofluid in macroscale and microscale channels are discussed. Finally, analysis and discussion of the existing correlations and models with the relevant physical properties are presented. According to this comprehensive review, future research needs have been identified. So far, fundamentals of boiling heat transfer and CHF phenomena of nanofluids have not yet been well understood. Therefore, systematic accurate experiments and flow regime observations of boiling heat transfer and CHF phenomena with various types of nanofluids under a wide range of test conditions should be emphasized. Furthermore, physical mechanisms, theory and prediction methods for boiling heat transfer, two phase flow and CHF characteristics should be targeted at in the future. Practical application of nanofluid two phase flow and heat transfer should also be considered.
\end{abstract}

Keywords: Nanofluid, Nucleate Boiling, Flow Boiling, Two Phase Flow, Critical Heat Flux, Heat Transfer And Mechanisms.

\section{Introduction}

As a new type of heat transfer medium, nanofluids have been attracting tremendous attention in the field of thermal science and engineering due to their high thermal conductivity, unique colloidal property and heat transfer behaviours. Over the past decade, a large number of fundamental investigations on heat transfer and heat transfer mechanisms have been conducted [1-4]. Furthermore, investigations on flow boiling and CHF in microchannel have also been conducted to explore a new approach for high heat flux cooling in various engineering applications [5-11]. Investigation of boiling heat transfer and two phase flow of nanofluids in microchannel and confined spaces is becoming an important topic [12, 13]. However, quite controversial and contradictive results have been obtained from different studies [1, 2]. As a new interdisciplinary research frontier subject of nanotechnology, two-phase flow, thermal physics and engineering heat transfer, there are still big challenges of fundamental research and applications of boiling heat transfer, two phase flow and $\mathrm{CHF}$ with nanofluids. In this review, the issues of fundamentals, mechanisms and technology development of boiling heat transfer, two phase flow and CHF are reviewed and future research needs have been identified.

\section{Thermal Physical Properties of Nanofluids}

Nucleate pool boiling heat transfer, flow boiling heat transfer, CHF and two phase flow characteristics of nanofluids strongly depend on the accurate knowledge of thermal physical properties. So far, most studies on nanofluid thermal properties have focused on the thermal conductivity of nanofluids. Some studies have concerned viscosity and the specific heat of nanofluids. More recently, several studies have addressed the latent of heat of evaporation of nanofluids. Some researchers measured the surface roughness of the heat transfer surface due to the nanoparticle deposition. Although models have also been proposed for some physical properties, such models are only applicable to some nanofluids and limited conditions. Even for the same type of nanofluid, there is no agreed method predicting the physical properties. 
Numerous studies of enhancement of thermal conductivities of various nanofluids have been extensively conducted [13-18]. Eastman et al. [14] have found that a small amount (about $0.3 \%$ by volume fraction) of copper nanoparticles of mean diameter $<10 \mathrm{~nm}$ in ethylene glycol increased this fluid's inherently poor thermal conductivity by $40 \%$. Figure 1 shows their results for the effective thermal conductivity of ethylene glycol. The largest increase in thermal conductivity was obtained for a nanofluid which contained a small quantity of thioglycolic acid to improve the stability of the metallic particles against settling. Their experimental results show that the nanofluids have substantially higher thermal conductivities compared to the base fluid. The nanofluid thermal conductivity increases with the nanoparticle volume fraction. Furthermore, CNTs have been extensively investigated to act nanoparticles for nanofluids. CNTs have unusually high thermal conductivity up to $6600 \mathrm{~W} / \mathrm{mK}$ [17] and thus can enhance the thermal conductivity of nanofluids and heat transfer characteristics. The first reported work on a single walled carbon nanotube (SWCNT)-polymer epoxy composite by Biercuk et al. [16] demonstrated a $70 \%$ increase in thermal conductivity at $40 \mathrm{~K}$, rising to $125 \%$ at room temperature with $1 \mathrm{wt} . \%$ nanotube loading. They also observed that thermal conductivity increased with increasing temperature. Choi et al. [18] measured thermal conductivities of oil suspensions containing multiwalled carbon nanotubes up to 1 vol.\% loading and found similar behavior, in this case, a $160 \%$ enhancement. The existing thermal conductivity models for conventional solid/liquid systems have been used to estimate the effective conductivities of nanofluids due to the absence of a theory for thermal conductivities of nanofluids. However, measured thermal conductivities are substantially greater than theoretical predictions. Furthermore, since nanoparticles can form nano or microstructures, the thermal conductivity of such a nanofluid under static conditions could be quite different under flow conditions.

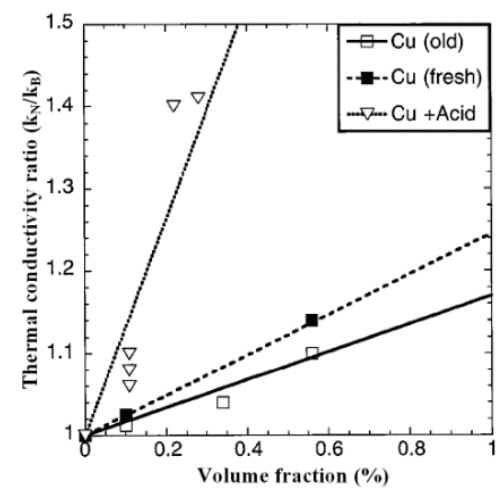

Fig. 1: The effective thermal conductivity of ethylene glycol is improved by up to $40 \%$ through the dispersion of $0.3 \mathrm{vol} . \% \mathrm{Cu}$ nanoparticles [14].

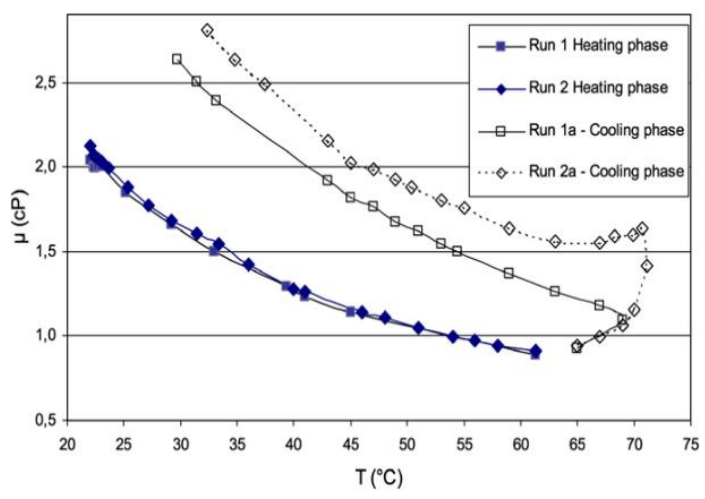

Fig. 2: Hysteresis observed for water- $\mathrm{Al}_{2} \mathrm{O}_{3}-47 \mathrm{~nm}, 7 \%$ particle volume fraction [21].

Several studies have reported the measured viscosities of nanofluids which show quite different behaviours [19-22]. The viscosities of nanofluids are normally much higher than that of their base fluids. Viscosity is a strong function of temperature and the volumetric concentration of nanoparticles while the particle-size effect seems to be important only for sufficiently high particle fractions. Nguyen et al. [21] investigated the effects of temperature and particle volume concentration on the dynamic viscosity of water- $\mathrm{Al}_{2} \mathrm{O}_{3}$ nanofluids at temperatures from 22 to $75^{\circ} \mathrm{C}$. They found a 
hysteresis phenomenon of the measured viscosities as shown in Fig. 2. For a given particle volume concentration, there is a critical temperature beyond which nanofluid viscous behaviour becomes drastically altered. If a fluid sample is heated beyond such a critical temperature, a striking increase of viscosity occurs. If it is cooled after being heated beyond this critical temperature, then a hysteresis phenomenon occurs. Such an intriguing hysteresis phenomenon and mechanisms are poorly understood. Furthermore, the critical temperature was found to be strongly dependent on both particle fraction and size. It is unknown if this phenomenon exists for all other nanofluids as no such phenomenon was reported by other research groups. Ding et al. [22] measured the viscosity of water based CNT nanofluids. They found that the viscosity of CNT nanofluids increased with increasing the CNT concentration and decreasing temperature. The CNT nanofluid exhibits non-Newtonian characteristics with a shear thinning behaviour. Although several models and prediction methods have been developed for the viscosities of nanofluids, there are big discrepancies of the measured viscosities and the calculated values for other nanofluids. This is mainly due to the controlling factors which may significantly affect the fluid behaviours, such as nano-particle materials, nanoparticle size and shape, the concentration, $\mathrm{pH}$ and temperatures etc.

Some studies have shown that the specific heat can be enhanced using nanoparticles [23-25]. However, the physical mechanisms are not fully understood and there is no systematic theory or reliable prediction methods for the specific heat of nanofluids. The specific heat of a nanofluid depends on the specific heat of the base fluid and the nanoparticle, the volume concentration of nanoparticles and the temperature. Nelson and Banerjee [25] used a differential scanning calorimeter for measurement of specific heat capacity of exfoliated graphite nanoparticle fibers suspended in polyalphaolefin at mass concentrations of 0.6 and $0.3 \%$. They found an increase in the specific heat of the nanofluid with increase in the temperature. The specific heat capacity of the nanofluid was found to be enhanced by $50 \%$ compared with $\mathrm{PAO}$ at $0.6 \%$ concentration by weight. Furthermore, the latent heat of evaporation for nanofluids is critical in investigating boiling heat transfer and CHF phenomena and models, However, the relevant research is rare in the literature. More recently, several researchers measured the latent heat of evaporation of nanofluids [26, 27]. Both the latent heat of evaporation can be enhanced and decreased with nanofluids. However, systematic knowledge and mechanisms of latent heat enhancement or decrease with nanofluids have not yet established. Furthermore, no systematic knowledge of surface tension and contact angle which are also important in understanding the boiling and two phase CHF phenomena.

\section{Nucleate Pool Boiling Heat Transfer and CHF with Nanofluids}

Studies on nucleate pool boiling heat transfer and CHF phenomena with nanofluids have been extensively conducted over the past decade. However, some studies show a decrease or no change in nucleate boiling heat transfer with nanofluids while others show an increase in the heat transfer. Furthermore, quite different heat transfer mechanisms are proposed to explain the phenomena and experimental results.

\subsection{Nucleate Pool Boiling Heat Transfer and Mechanisms with Nanofluids}

Nucleate boiling heat transfer enhancement has been reported [28-30, 32, 33]. Yang and Maa [28] conducted pool boiling heat transfer experiments using $\mathrm{Al}_{2} \mathrm{O}_{3}$ nanofluids in 1984, which might be the first research in this field. According to their experimental results, low concentrations of $\mathrm{Al}_{2} \mathrm{O}_{3}$ nanofluids with $50 \mathrm{~nm}$ diameter can enhance the nucleate pool boiling heat transfer. Ghopkar et al. [29] reported that $\mathrm{ZrO}_{2}$-water could enhance nucleate pool boiling heat transfer at low particle volumetric concentrations but the boiling heat transfer decreases with further increasing in the nanoparticle concentration in the nanofluid. They mentioned that addition of a surfactant to the nanofluids drastically decreased heat transfer whereas surfactants often increase nucleate boiling heat transfer. This may depend on the types of surfactants [31]. However, whether a surfactant is used or not is not mentioned in many available studies. Furthermore, the combined function of surfactants and nanoparticles should be systematically investigated to understand the phenomena and mechanisms. Some studies have shown that nanoparticles do not enhance nucleate pool boiling heat transfer or decrease it. Das et al. [32] conducted an experimental investigation on nucleate pool boiling heat transfer characteristics of $\mathrm{Al}_{2} \mathrm{O}_{3^{-}}$ water nanofluids under atmospheric conditions. They speculated that the deterioration in boiling heat transfer was not due to a change in the fluid property but due to the change in the surface wettability due to the entrapment of nanoparticles in the surface cavities which reduced the boiling nucleates. Kim et al. [33] found that heat transfer coefficients of $\mathrm{Al}_{2} \mathrm{O}_{3}$-water nanofluids remained unchanged compared to those of water. Furthermore, it is important to report weather the experimental results are repeatable or not. Such information is generally missing in most studies.

Without a stable agent, deposition of nanoparticles may occur after some time in most case. In this case, the reported experimental results cannot be repeated due to the deposition of nanoparticles. Surfactants are generally used as stable 
agents in preparing nanofluids. It is important to understand how surfactants affect the nucleate boiling heat transfer behaviours because surfactants may enhance or deteriorate the heat transfer behaviours [31]. Xia et al. [13] recently conducted systematic experimental investigation on nucleate pool boiling heat transfer of multi-walled carbon nanotubes (MWCNTs) water-based nanofluids in a confined space. The effects of various surfactants and the change of boiling heat transfer surface conditions due to the nanoparticle deposition have been investigated in their study. The effects of four different surfactants on the stability of the nanofluids were investigated and the suitable surfactant gum acacia (GA) was selected as the stable agent for the nanofluids for the boiling experiments. Furthermore, GA with four different mass fractions of $0.1 \%, 0.3 \%, 0.5 \%$ and $0.7 \%$ was respectively dissolved in the base fluids to investigate the effect of the surfactant concentration on the stability of the nanofluids. They found that the MWCNTs nanofluids enhanced the nucleate boiling heat transfer. Figure 3(a) shows the variation of heat flux versus the superheat degree for the boiling processes with the MWCNTs nanofluids with three volume concentrations of $0.005 \%, 0.01 \%$ and $0.05 \%$ and the deionized water at the steady state test conditions. Figure 3(b) shows the variation of boiling heat transfer coefficient versus the heat flux for the corresponding test fluids respectively. The experimental results demonstrate that the nanofluids lead to reducing the boiling surface temperatures compared to those of water under the same heat flux. This means that addition of the MWCNTs in the deionized water can enhance the boiling heat transfer. This is mainly caused by the nanoparticle deposition on the boiling heat transfer surface which increased the surface roughness and thus increased the boiling nucleate sites. However, addition of surfactant GA can inhibit the deposition of the nanoparticles and thus may reduce the boiling heat transfer coefficient of the nanofluids. They explained that the mechanisms of the boiling heat transfer enhancement of the nanofluids at lower heat fluxes are different from those at higher heat fluxes. At lower heat fluxes, the nanoparticle deposition layer increases the frequency of bubble formation and thus the boiling heat transfer is enhanced while at the high heat fluxes, the boiling heat transfer processes may facilitate the nanoparticle deposition and the disturbance of the MWCNTs may increase the enhancement ratio of heat transfer coefficient with increasing the heat flux.

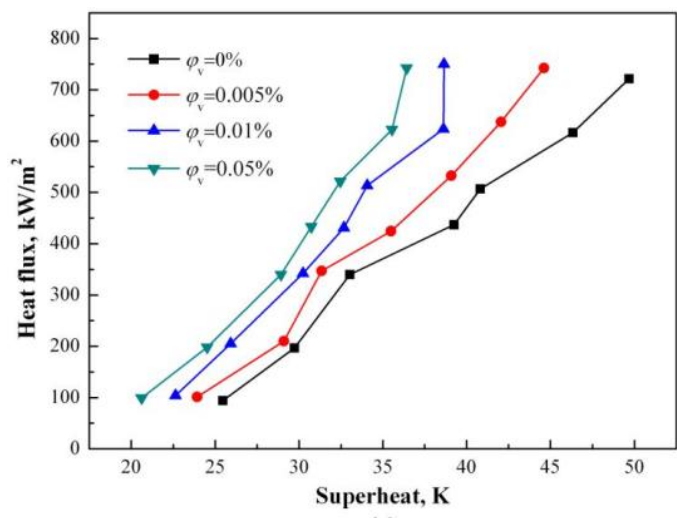

(a)

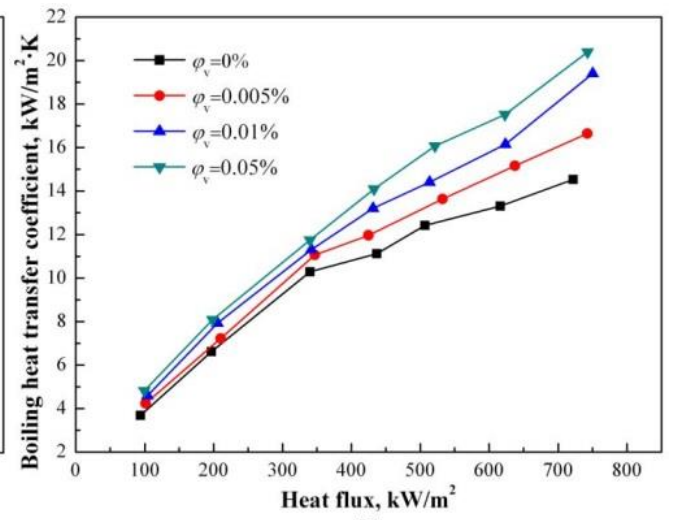

(b)

Fig. 3: Boiling curves of the MWCNTs nanofluids with three different volume concentrations of $0.005 \%, 0.01 \%$ and $0.05 \%$, and the deionized water: (a) Heat flux vs. superheat degree, (b) Boiling heat transfer coefficient vs. heat flux [13].

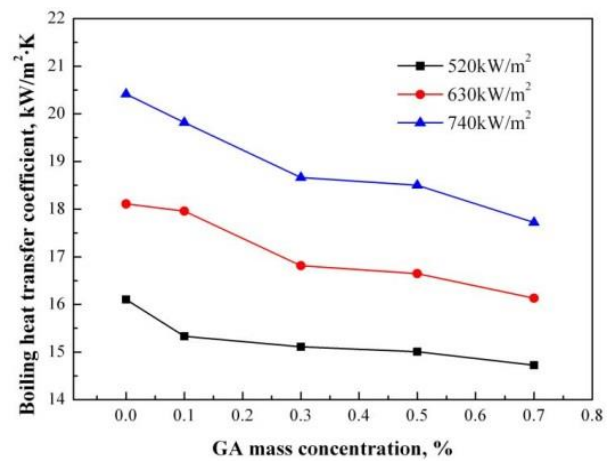

Fig. 4: Variation of the boiling heat transfer coefficient with the mass concentration of surfactant GA at three different heat fluxes [13]. 


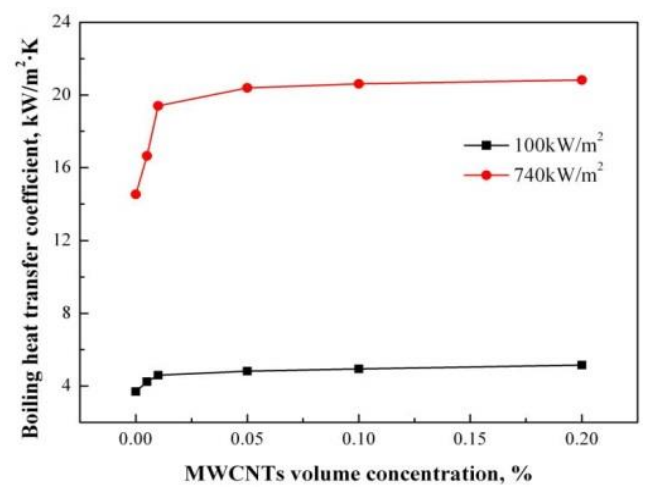

Fig. 5: Variation of the boiling heat transfer coefficients of the MWCNTs nanofluids with the concentrations at two different heat fluxes [13].

Figure 4 shows the variation of the boiling heat transfer coefficient with the mass concentration of GA at three different heat fluxes of 520,630 and $740 \mathrm{~kW} / \mathrm{m}^{2}$. It is obvious that the variations of the heat transfer coefficients clearly indicate that the boiling heat transfer is deteriorated with increasing the concentration of GA in the nanofluids. Furthermore, the heat transfer coefficient curves fall down sharply with increasing the heat flux. It means the negative effect of surfactant GA on the boiling heat transfer becomes more significant at a higher heat flux than those at a lower heat flux. Figure 5 shows the comparison of the boiling heat transfer coefficient with the MWCNTs volume concentration at a lower heat flux of $100 \mathrm{~kW} / \mathrm{m}^{2}$ and a higher heat flux of $740 \mathrm{~kW} / \mathrm{m}^{2}$. The heat transfer coefficients at the higher heat flux are around four times higher than those at the lower heat flux. It should be noted that there is a fast-increase in the nucleate boiling heat transfer coefficients occurred at lower concentrations of the nanofluids. However, there is a critical concentration of the nanofluids at which the boiling heat transfer enhancement remains unchanged beyond this critical concentration. They explained the heat transfer enhancement performance according the observed bubble dynamics. Initially, a bubble emerges on the boiling surface and kept growing. Shortly afterwards, it departures from the surface slowly which may deteriorate the heat transfer from the boiling surface to the fluid. At last, the liquid back to initial state without phase-change.

In general, the nucleate boiling heat transfer mechanisms mainly include the decreasing of active nucleation sites from nanoparticle sedimentation on the boiling surface, the change of wettability of the surface and nanoparticle coatings on the surface. Furthermore, bubble dynamics including bubble growth, bubble size and departure frequency were studied via visualization using a high-speed camera. Xia et al. [13] explained the heat transfer enhancement mechanisms by measuring the contact angles on a smooth surface and a deposited surface after boiling. They also observed the deposition of nanoparticles on the heat transfer surface. Furthermore, they observed the bubble behaviours using a high-speed video camera, which are used to explain the heat transfer enhancement mechanisms [13]. The MWCNTs in nanofluid without GA agglomerated and deposited at the bottom of nanofluid after boiling while the nanofluid with surfactant GA still keep good dispersion after boiling process. With increasing heat flux, the activity of nanoparticles is more severe in the liquid, which is helpful to the dispersion of nanoparticles by surfactant. However, the main reason for the enhancement of heat transfer by nanofluid is the aggregation layer of the nanoparticles on the boiling surface. According to this observation, the surfactant can make particles uniformly dispersed in the base fluid and inhibit the deposition generated on the boiling surface, reduce the roughness of boiling surface and weaken the active nucleation sites. One of the most commonly explanations for the boiling heat transfer enhancement and almost all explanations for the deterioration were the nanoparticle deposition on the heat transfer surface. However, the explanations for the mechanisms are diverse and even contradictory. In general, complete and systematic knowledge and fully understanding of the fundamentals and physical mechanisms of nucleate boiling heat transfer with nanofluids have not yet achieved. 


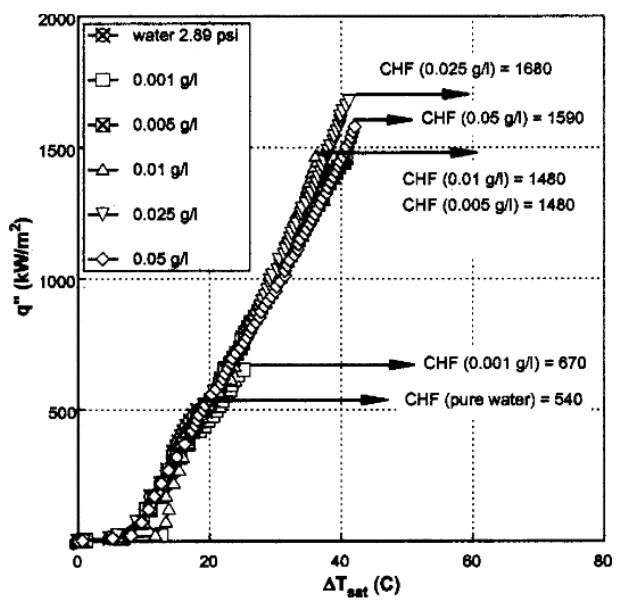

Fig. 6: Boiling curves at different concentrations of $\mathrm{Al}_{2} \mathrm{O}_{3}$-water nanofluids [34].

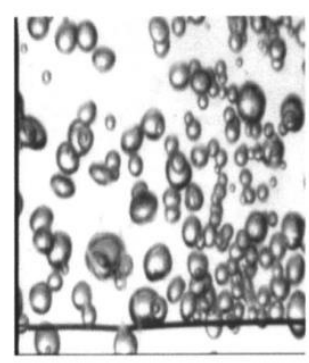

water

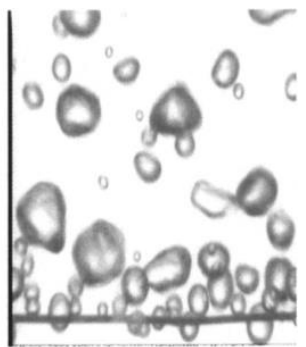

nanofluid

Fig. 7: Sample pictures of bubbles growing on a heated wire $\left(300 \mathrm{~kW} / \mathrm{m}^{2}\right)$ [34].

\subsection{CHF in Nucleate Pool Boiling and Mechanisms with Nanofluids}

Some studies have shown significant enhancement of the CHF in nucleate pool boiling with nanofluids [34-37]. You et al. [34] found drastic CHF enhancement for the pool boiling with $\mathrm{Al}_{2} \mathrm{O}_{3}$-water nanofluids. Figure 6 shows their experimental results for the CHF in pool boiling, where up to three times enhancement was achieved as compared to that of the base fluid. They also performed a visualization of the boiling process and found that the average size of departing bubbles increased but the frequency of departing bubble decreased. Figure 7 shows their observed bubble images. They concluded that the unusual CHF enhancement of nanofluids could not be explained by any existing CHF model, i.e. no pool boiling CHF model includes thermal conductivity or liquid viscosity and hence cannot explain this phenomenon, and the enhancement on liquid-to-vapour phase change was not related to the increased thermal conductivity. They also reported the enhancement in $\mathrm{CHF}$ for both horizontal and vertical surface orientations with the nanofluids. Noting a change of the roughness of the heater surface before and after their experiments, they hypothesized that the reason for the increase in the CHF might be due to a surface coating formed on the heater with nanoparticles. Furthermore, they also studied the effect of nanoparticle concentration on the CHF enhancement in pool boiling. The CHF enhancement ratio increases with increasing the nanoparticle concentration in general. However, there is a critical concentration beyond which the CHF enhancement ration remains constant at the maximum enhancement value.

It seems that the CHF enhancement in the nucleate pool boiling with nanofluids is mainly caused due to the deposited porous coating on the boiling heat transfer surface and change of the surface conditions [38-40]. The thin nanoparticle porous layer deposited on the heat transfer surface during nucleate boiling of nanofluids and thus the CHF can be enhanced due to the improved wettability of the heating surface as the liquid can be absorbed into the heating surface through the capillary function the micro-pores in the nanoparticle porous layer. However, completely and systematic definite theory and physical mechanisms linking the improved wettability and the CHF enhancement on the nanoparticle layer have not yet been developed due to the complicated phenomena of nucleate pool boiling and CHF with nanofluids. 


\section{Flow Boiling Heat Transfer and CHF with Nanofluids}

Both flow boiling heat transfer and $\mathrm{CHF}$ enhancement and deterioration have been reported in the literature. Furthermore, various mechanisms have been proposed to explain the heat transfer and CHF phenomena in flow boiling.

\subsection{Flow Boiling Heat Transfer and CHF with Nanofluids in Macroscale Channels}

Khandekar et al. [41] investigated the overall thermal resistance of a closed two-phase thermosiphon using water and various water based nanofluids $\left(\mathrm{Al}_{2} \mathrm{O}_{3}, \mathrm{CuO}\right.$ and laponite clay) as working fluids. All these nanofluids showed inferior thermal performance relative to pure water. However, Henderson et al. [42] investigated flow boiling of R134a based nanofluids in a horizontal tube and have found flow boiling could be enhanced. Some reported noticeable decrease in the heat transfer coefficient was observed and a liquid film of high particle concentration may be formed on the tube surface. No agreement on the heat transfer mechanisms have been reached so far. Liu et al. [43] reported that boiling heat transfer in their thermosphon was greatly enhanced using a $\mathrm{Cu}$-water nanofluid in a miniature thermosyphon as shown in Fig. 8. Liu et al. [45] studied in a flat heat pipe evaporator and found that the heat transfer coefficient and the CHFs of CuO-water nanofluids were enhanced by about $25 \%$ and $50 \%$, respectively, at atmospheric pressure whereas about $100 \%$ and $150 \%$, respectively, at a pressure of $7.4 \mathrm{kPa}$. They also found that there was an optimum mass concentration for attaining a maximum heat transfer enhancement. Furthermore, Liu and Qiu [46] studied boiling heat transfer and CHF of jet impingement with $\mathrm{CuO}$-water nanofluids on a large flat surface and found that boiling heat transfer was deteriorated while the CHF was enhanced compared to that of pure water. Park et al. [47] studied flow boiling of nanofluids in a horizontal plain tube having an inside diameter of $8 \mathrm{~mm}$. A noticeable decrease in the heat transfer coefficient was observed in their study. A liquid film of high particle concentration may be formed on the tube surface. Akhavan-Behabadi et. al. [48] investigated the effect of $\mathrm{CuO}$ nanoparticles on flow boiling heat transfer of R600a-Polyester mixture (99/1) inside a horizontal smooth tube having an inner diameter of $8.26 \mathrm{~mm}$. The nanoparticle concentrations of $0.5-1.5 \mathrm{wt} . \%$. They found that the nano particles enhanced the flow boiling heat transfer. A maximum heat transfer enhancement up to $63 \%$ was achieved at the highest concentration of $1.5 \mathrm{wt} \%$. Nikkhah et al. [49] conducted experiments of flow boiling with $\mathrm{CuO} /$ water nanofluids in an upward conventional heat exchanger. They analyzed the surface images taken with the digital microscopic imaging system and found that the thickness of deposited layer and roughness of surface significantly increased with increasing time, which could affect the wettability of surfaces and the contact angle of bubbles. The higher fouling resistances were measured with increasing concentration and mass flux of nanofluids. However, the fouling resistances were significantly reduced with increasing the wall temperature at higher heat flux when the heat transfer was changed from the convection dominated heat transfer to the nucleate boiling dominated heat transfer. It should be mentioned that fouling should be avoided in practical application. If the heat transfer enhancement is caused due to the fouling of nanoparticles on the tube surface. It would use a coating to enhance the flow boiling heat transfer rather than using a nanofluid. Paul et al. [50] investigated the rewetting phenomenon in a vertical tube with bottom flooded by $\mathrm{Al}_{2} \mathrm{O}_{3}$ /water nanofluids, with emphasis on estimating the apparent rewetting temperature and the construction of boiling curve from the temperature-time responses recorded during the rewetting phenomenon. They found that the rewetting of the nanofluids took place faster than in pure water and therefore the heat transfer and CHF were enhanced due to the rewetting. They conjectured that the deposition of nanoparticles resulted in the formation of micro-cavities and in turn altered the surface wettability and roughness, which thereby led to the heat transfer and CHF enhancements and an earlier collapse of vapour film. According to the available studies, the heat transfer enhancement in flow boiling with nanofluids are mainly attributed to the following key mechanisms: The nanoparticle deposition on the heated surface, The reduction of the boundary layer height due to the disturbance of nanoparticles and the formation of molecular adsorption layer on the surface of nanoparticles, The inhibition of the dry patch development by the structural disjoining pressure and the enlarged percentage of liquid film evaporation heat transfer region with the nanoparticles, Higher thermal conductivity or high viscosity of nanofluid due to the nanoparticle addition and Improved bubble dynamics and flow patterns due to nanoparticle suspension. However, understanding of the heat transfer mechanisms of flow boiling with nanofluids is far from sufficient due to the very complicated phenomena and mechanisms. Furthermore, there are quite contradictory results from different studies. The modification of the surface wettability due to the nanoparticle deposition on the heat transfer surface is one of the main explanations for the flow boiling heat transfer enhancement by some researchers while it is also one of the most commonly explanations for the heat transfer deterioration by others. 


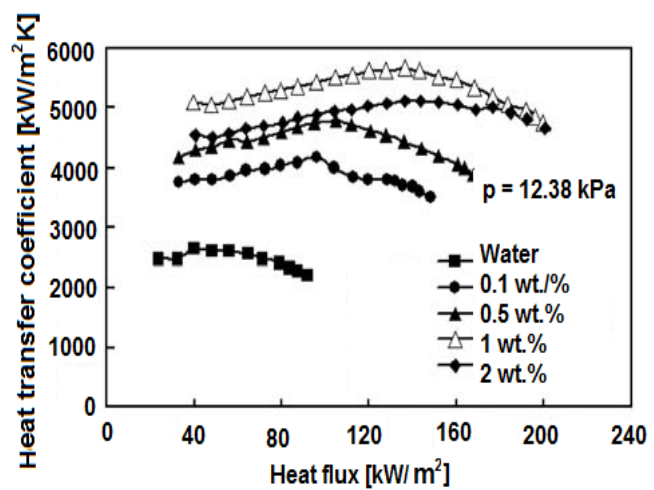

Fig. 8: Effect of mass concentration of nanoparticles on boiling heat transfer coefficient of CuO-water nanofluids [43].

A number of studies of CHF with nanofluids have been conducted to understand the phenomena and mechanisms. For the $\mathrm{CHF}$ in nanofluid flow boiling, most of the available studies have reported the CHF enhancement [51-57]. The maximum enhancement could reach100\%. Kim et al. [51, 52] conducted internal flow boiling CHF experiments of flow boiling with dilute alumina, zinc oxide, and diamond water-based nanofluids inside tube. They varied the concentration of the nanofluids from 0.001 vol. \% to 0.1 vol. $\%$, and the mass flux from $1000 \mathrm{~kg} / \mathrm{m}^{2}$ s to $2500 \mathrm{~kg} / \mathrm{m}^{2} \mathrm{~s}$. They found that the nanofluids exhibited a significant CHF enhancement with respect to pure water at high mass fluxes of $2000-2500 \mathrm{~kg} / \mathrm{m}^{2} \mathrm{~s}$. However, there was no enhancement at a lower mass flux of 1000 to $1500 \mathrm{~kg} / \mathrm{m}^{2} \mathrm{~s}$. They suggested that some nanoparticles were deposited on the boiling surface during the experiments. Such particle deposition increased the wettability of the boiling surface. Kim et al. [56, 57] reported nanoparticle deposition on the heater surface after nanofluid flow boiling and considered this to be the main cause behind the observed CHF enhancement. They found CHF enhancement of up to $70 \%$, with a nanoparticle content of less than $0.01 \%$ by volume of alumina in water. This again shows that only a small nanoparticle concentration is required to obtain dramatic CHF enhancements during nanofluid flow boiling. Several studies on $\mathrm{CHF}$ with various nanofluids under different test conditions have been conducted in various channels. These covers the low pressure and low flow conditions, the effect of micro/nanoscale structures on CHF, flow boiling in downward-facing channels, CHF with magnetic nanofluids and magnetic field effect on CHF with ferrofluid in annulus [58-62]. In general, CHF enhancement has been achieved but understanding the mechanisms is quite different and this needs to be further investigated. Most available studies have attributed the CHF enhancement to the nanoparticle deposition on the heat transfer surface because it decreases the surface contact angle and thus modified the surface wettability. Other explanations on the CHF enhancement include the following key mechanisms: It enhances lateral wicking of liquid into the microlayer regions of the evaporating meniscus, causing a slower rise in local wall temperature. It increases available active nucleation sites. It yields faster rewetting which results in an earlier collapse of vapor film on the heat transfer surface. Understanding of mechanisms of heat transfer and CHF enhancement of nanofluid flow boiling is insufficient so far. Further effort should be made to understand the mechanisms and possibly lead to achieving well developed theory and models. Especially, no relevant research on the influence of two phase flow patterns on flow boiling heat transfer and CHF is available in the literature because flow patterns are intrinsically correlated to the flow boiling heat transfer and CHF phenomena.

\subsection{Flow Boiling Heat Transfer and CHF of Nanofluids in Microscale Channels}

In recent years, several studies were conducted to investigate the flow boiling heat transfer and CHF behaviours with nanofluids in mini- and micro-channels [63-71]. However, such research is very limited. Systematic knowledge, mechanisms and theory on the topics have not yet established. Use of nanofluids appears promising in several aspects of flow boiling heat transfer and two-phase flow in microchannels, but still faces several challenges: (i) the lack of agreement between experimental results from different research groups and (ii) the lack of theoretical understanding of the underlying mechanisms with respect to nanoparticles.

Lee and Mudawar [64] conducted flow boiling experiments in a micro-channel heat sink using pure water and a $1 \%$ $\mathrm{Al}_{2} \mathrm{O}_{3}$ nanofluid solution. But they suggested that nanofluids should not be used in microchannels due to the deposition of the nanoparticles. No measured flow boiling heat transfer coefficients were presented in their study. Chehade et al. [65] conducted an experimental study on nanofluid convective boiling heat transfer in parallel rectangular minichannels of 800 $\mu \mathrm{m}$ hydraulic diameter. Their experiments were conducted with pure water and silver nanoparticles suspended in a water 
base fluid. The experimental results showed that the local heat transfer coefficient, local heat flux, and local wall temperature were affected by silver nanoparticle concentration in a water base fluid. For the same mass flux, the average heat transfer coefficient is larger for nanofluids than that of pure water. The heat transfer coefficient increases with increasing the nanoparticle concentration. The maximum enhancement of the average heat transfer coefficient is about $132 \%$ for $25 \mathrm{mg} / \mathrm{L}$ and $162 \%$ for $50 \mathrm{mg} / \mathrm{L}$. In addition, the boiling local heat transfer enhancement by adding silver nanoparticles in base fluid is not uniform along the channel flow. Better performances and the highest effect of nanoparticle concentration on the heat transfer were obtained at the minichannel's entrance.

Few studies on flow boiling and CHF of nanofluids in microscale channels and surface coating effects and showed enhanced heat transfer and CHF behaviours with nanofluids. Duursma et al. [66] conducted experiments of subcooled flow boiling with $\mathrm{Al}_{2} \mathrm{O}_{3}$ /ethanol nanofluids in horizontal, rectangular, high-aspect-ratio microchannels. The results showed that nanoparticles enhanced the boiling heat transfer significantly, with a peak at the concentration of $0.05 \%$. The two-phase visualizations observed bubble confinement and deformation. The study of heat and mass transfer near the three-phase contact line revealed the important role played by this zone in two-phase flow boiling in microchannels. Khanikar et al. [67] performed flow boiling experiments in a carbon nanotube (CNT)-coated copper microchannel. They used just water as the working fluid. Appreciable differences in the influence of the CNT coating were observed at high rather than low mass velocities. The $\mathrm{CHF}$ was repeatable at low mass velocities, but degraded following repeated tests at high mass velocities, demonstrating that high flow velocities caused appreciable changes in the morphology of the CNT-coated surface. While the CHF was enhanced by the increased heat transfer area associated with the CNT coating, the enhancement decreased following repeated tests because the CNT fin effect was compromised by the bending. This result also supported the relationship between flow boiling CHF enhancement and the nanoparticle-deposited surface. Flow boiling CHF enhancement in nanofluids is strongly related to the surface wettability, which is similar to the pool boiling CHF enhancement. Further experimental data need to be collected on the flow boiling of nanofluids to obtain a more substantial database and a better understanding of nanofluid flow boiling mechanisms. In contrast with pool boiling, the flow boiling $\mathrm{CHF}$ in nanofluids is still being investigated and strongly needed. Vafaei and Wen $[68,69]$ investigated flow boiling heat transfer of aqueous alumina nanofluids in single microchannels with particular focuses on the CHF and the potential dual roles played by nanoparticles, i.e., (i) modification of the heating surface through particle deposition and (ii) modification of bubble dynamics through particles suspended in the liquid phase. Their flow boiling experiments reveal a modest increase in CHF by nanofluids, being higher at higher nanoparticle concentrations and higher inlet subcoolings. The bubble formation experiments show that suspended nanoparticles in the liquid phase alone can significantly affect bubble dynamics. Figure 30 shows their measured CHF Data of alumina nanofluids with two concentrations $(0.011$ vol. $\%$ and 0.1 vol.\%) at a subcooling of $45^{\circ} \mathrm{C}$. It shows that the CHF increases with increasing concentration in their study. However, the very limited studies are not sufficient to understand the fundamentals and mechanisms of flow boiling heat transfer and $\mathrm{CHF}$ phenomena in microchannels. It is essential to conduct systematic experiments in the relevant topics. Furthermore, new theoretical study is needed to explain and predict the results. One could also note that some nanofluids coat the heat transfer surfaces, and hence this may significantly influence the results. The surface effects need to be clearly separated from the fluidic effects in order to deduce the actual trends in the nanofluid data and thus build new models.

\section{Analysis and Discussion}

It is very helpful to understand the phenomena and mechanisms through analyzing the existing correlations and models for boiling heat transfer and CHF by incorporating and considering the relevant nanofluid physical properties. Examining widely quoted correlations for nucleate pool boiling heat transfer, it is not evident as to how a nanofluid will have an influence. For example, the Cooper [72] correlation is based on the reduced pressure $p_{r}$ but nothing is known about the effect of nanofluids on the critical pressure or vapor pressure curve.

$$
h_{n b}=55 p_{r}^{0.12-0.2 \log _{10} R_{p}}\left(-\log _{10} p_{r}\right)^{-0.55} M^{-0.5} q^{0.67} C
$$

where $h_{n b}$ is nucleate boiling heat transfer coefficient, $R_{p}$ is surface roughness $(\mu m), M$ is molecular weight, $q$ is heat flux and $C$ is a constant which is 1 for horizontal plane surfaces and 1.7 for horizontal copper tubes according to Cooper's original paper. However, comparison with experimental data suggests that better agreement is achieved if a value of 1 is used also for horizontal tubes. Note that the heat transfer coefficient is a fairly weak function of the surface roughness 
parameter $R_{p}$, which is seldom well known. A value of $R_{p}=1$ is suggested for technically smooth surfaces. Thus, a nanocoating may have an effect but would be very small.

Taking the Forster and Zuber [73] correlation:

$$
h_{n b}=0.00122\left[\frac{k_{L}^{0.79} c_{p L}^{0.45} \rho_{L}^{0.49}}{\sigma^{0.5} \mu_{L}^{0.29} h_{L V}^{0.24} \rho_{V}^{0.24}}\right] \Delta T_{s a t}^{0.24} \Delta p_{s a t}^{0.75}
$$

it would predict an increase in heat transfer coefficients through the increase in liquid thermal conductivity and a decrease in heat transfer coefficients by the increase in liquid viscosity and surface tension. In Eq. (7), $k_{L}$ is liquid thermal conductivity, $c_{p L}$ is liquid specific heat, $\rho_{L}$ and $\rho_{V}$ are liquid and vapor density, $\sigma$ is surface tension, $\mu_{L}$ is liquid dynamic viscosity, $h_{L V}$ is latent heat, $\Delta T_{\text {sat }}$ and $\Delta p_{\text {sat }}$ are the superheated temperature and pressure.

Taking the Stephan and Abdelsalam [74] correlation for water derived by multiple regression:

$$
\begin{gathered}
h_{n b}=0.0546\left[\left(\frac{\rho_{V}}{\rho_{L}}\right)^{1 / 2}\left(\frac{q D_{b u b}}{k_{L} T_{s a t}}\right)\right]^{0.67}\left(\frac{h_{L V} D_{b u b}^{2}}{a_{L}^{2}}\right)^{0.248}\left(1-\frac{\rho_{V}}{\rho_{L}}\right)^{-4.33} \frac{k_{L}}{D_{b u b}} \\
D_{b u b}=0.0146 \beta\left[\frac{2 \sigma}{g\left(\rho_{L}-\rho_{V}\right)}\right]^{1 / 2}
\end{gathered}
$$

Here $D_{b u b}$ is bubble departure diameter, the contact angle $\beta$ is assigned a fixed value of $35^{\circ}$ irrespective of the fluid, $T_{\text {sat }}$ is the saturation temperature of the fluid in $K, a_{L}$ is the liquid thermal diffusivity and $g$ is gravity constant. It can be summarized that the dependency of heat transfer on the liquid thermal conductivity, density and viscosity are as follows:

$$
\begin{array}{ll}
\text { - } & h_{n b} \propto k_{L}^{-0.166} \\
\text { - } & h_{n b} \propto \sigma^{0.083}
\end{array}
$$

Thus, it would predict a decrease in heat transfer coefficients through the increase in liquid thermal conductivity and an increase in heat transfer coefficients by the increase in surface tension while no liquid viscosity effect is concerned.

On the other hand, neither liquid thermal conductivity nor liquid viscosity is found in the critical heat flux model of Lienhard and Dhir [75] for pool boiling:

$$
q_{c r i t}=0.149 h_{L V} \rho_{V}\left[\frac{\sigma g\left(\rho_{L}-\rho_{V}\right)}{\rho_{V}^{2}}\right]^{1 / 4}
$$

where $q_{\text {crit }}$ is critical heat flux (CHF). According to this correlation, CHF increases with increasing surface tension and liquid density. On the other hand, $q_{c r i t}$ is only proportional to $\sigma^{1 / 4}$, so its effect is rather weak.

With respect to flow boiling heat transfer models, the nanofluid effect on the nucleate boiling contribution would be the same as in the previous section, utilizing the convective heat transfer correlation for annular flow of Kattan et al. [76]:

$$
\begin{gathered}
h_{c b}=0.0133 \operatorname{Re}_{L}^{0.69} \operatorname{Pr}_{L}^{0.4} \frac{k_{L}}{\delta} \\
\operatorname{Re}_{L}=\frac{4 \rho_{L} u_{L} \delta}{\mu_{L}}
\end{gathered}
$$




$$
\operatorname{Pr}_{L}=\frac{c_{p L} \mu_{L}}{k_{L}}
$$

where, $h_{c b}$ is convective heat transfer coefficient, $R e_{L}$ is liquid film Reynolds number, $P r_{L}$ is liquid Prandtl number and $\delta$ is liquid film thickness. It can be summarized that the dependency of heat transfer on the liquid thermal conductivity, density and viscosity are as follows:

$$
\begin{array}{ll}
\text { - } & h_{c b} \propto k_{L}^{0.6} \\
\text { - } & h_{c b} \propto \mu_{L}^{-0.29}
\end{array}
$$

Thus, this predicts an increase in heat transfer coefficient through the increase in the liquid thermal conductivity but a decrease in heat transfer coefficient by the increase in liquid viscosity, while no surface tension effect is concerned.

Regarding the critical heat flux in saturated flow boiling in microchannels, the recent empirical correlation of Wojtan et al. [77]:

$$
\begin{gathered}
q_{\text {crit }}=0.437\left(\frac{\rho_{V}}{\rho_{L}}\right)^{0.073} W e_{L}^{-0.24}\left(\frac{L_{H}}{D}\right)^{-0.72} G h_{L V} \\
W e_{L}=\frac{G^{2} L_{H}}{\rho_{L} \sigma}
\end{gathered}
$$

can be used for the analysis here, where $W e_{L}$ is Weber number based on heated length, $D$ is tube diameter, $L_{H}$ is heated length and $G$ is mass flux. Similar to the critical heat flux model of Lienhard and Dhir [100] for pool boiling, neither liquid thermal conductivity nor liquid viscosity is found in this expression. However, critical heat flux increases with increasing surface tension and liquid density according to this expression. So far, the lack of knowledge of these physical properties of nanofluids greatly limits an evaluation of the possible effect. This also poses a serious question: which physical properties should we use to reduce experimental data for nanofluids? The data reduction methods used might be one of the reasons why the available experimental are contradictory.

\section{Conclusions and Future Research Needs}

The following conclusions have been obtained and future research needs have been identified according to this comprehensive review and deep analysis:

1) Physical properties should be systematically investigated to set up a consistent database of physical properties and to further develop generalized prediction methods and models for the physical properties.

2) The inconsistencies between different studies on nucleate pool boiling heat transfer and CHF should be clarified. Furthermore, the effects of nanoparticle size and type on heat transfer and CHF should be studied. The boiling heat transfer mechanisms responsible for these trends should be identified and be able to explain why nucleate heat transfer and CHF may be enhanced, no change or decreased. Furthermore, a new model for CHF should be developed according to the experimental nanofluid data and the CHF mechanisms.

3) More experimental studies on nanofluid two-phase flow, flow boiling heat transfer and CHF should be conducted in both macroscale channels to evaluate the potential benefits of nanofluids. These should also include heat transfer performance, CHF, two-phase flow patterns and pressure drop in various types of channels including both macroscale and microscale channels.

4) The sediment or coating of nanoparticles on the boiling heat transfer surface is a big question that needs to be resolved. For example, if such a coating is beneficial, then it could be applied more easily using a coating process rather 
than nanofluid deposition. If such a nanoparticle layer has adverse effects, then ways to prevent it are needed or the correct nanofluids should be found.

5) Two phase flow regimes are critical in understanding relevant boiling heat transfer and CHF phenomena. However, little research has been conducted in this respect. Furthermore, no prediction methods and models for boiling heat transfer and CHF are available so far. Therefore, models and prediction methods that include the nano-particle effects on the flow regimes should be developed based on accurate measurements and observations of two phase flow, boiling heat transfer and CHF with nanofluids.

6) From a practical point of view, considering application of nanofluids to actual thermal-flow systems, good stability of nanoparticles is one of the critical necessary conditions. Surfactants are generally used to improve dispersion stability of nanoparticles. However, surfactants may enhance or deteriorate the boiling heat transfer and CHF. It is essential to clarify the effects of surfactants on the experimental results. The combined function of surfactants and nanoparticles should be systematically investigated to understand the physical mechanisms.

7) The economic evaluation of the heat transfer and CHF enhancement with nanofluids should be performed. If the technology is not economic, it is not necessary to develop such a technology. Otherwise, new feasible application of nanofluids should be explored.

\section{Nomenclature}

\section{$D$}

$D_{b u b}$

$G$

$g$

$h_{c b}$

$h_{L V}$

$h_{n b}$

$k_{L}$

$L_{H}$

$M$

$\operatorname{Pr}_{L}$

$p_{r}$

$q$

$q_{\text {crit }}$

$R_{p}$

$\operatorname{Re}_{L}$

$T_{\text {sat }}$

$W e_{L}$

tube diameter, $\mathrm{m}$

bubble departure diameter, $\mathrm{m}$

mass flux, $\mathrm{kg} / \mathrm{m}^{2} \mathrm{~s}$

gravity constant, $9.81 \mathrm{~m} / \mathrm{s}^{2}$

convective heat transfer coefficient, $\mathrm{W} / \mathrm{m}^{2} \mathrm{~K}$

latent heat of evaporation, $\mathrm{J} / \mathrm{kg}$

nucleate boiling heat transfer coefficient, $\mathrm{W} / \mathrm{m}^{2} \mathrm{~K}$

liquid thermal conductivity, $\mathrm{W} / \mathrm{mK}$

heated length, $\mathrm{m}$

molecular weight, $\mathrm{kg} / \mathrm{kmol}$

liquid Prandtl number, defined by Eq. (8)

reduced pressure

heat flux, $\mathrm{W} / \mathrm{m}^{2}$

critical heat flux $(\mathrm{CHF}), \mathrm{W} / \mathrm{m}^{2}$

surface roughness, $\mu \mathrm{m}$,

liquid film Reynolds number, defined by Eq. (7)

saturation temperature of the fluid, $\mathrm{K}$

\section{Greeks}

$\begin{array}{ll}a_{L} & \text { liquid thermal diffusivity, } \mathrm{m}^{2} / \mathrm{s} \\ \beta & \text { contact angle, }{ }^{\circ} \\ \Delta p_{\text {sat }} & \text { superheated pressure, } \mathrm{Pa} \\ \Delta T_{\text {sat }} & \text { superheated temperature, } \mathrm{Pa} \\ \delta & \text { liquid film thickness, } \mathrm{m} \\ \mu_{f} & \text { viscosity of ambient fluid, } \mathrm{N} / \mathrm{m}^{2} \mathrm{~s} \\ \mu_{L} & \text { liquid dynamic viscosity, } \mathrm{N} / \mathrm{m}^{2} \mathrm{~s} \\ \rho_{L} & \text { liquid density, } \mathrm{kg} / \mathrm{m}^{3} \\ \rho_{V} & \text { vapor density, } \mathrm{kg} / \mathrm{m}^{3} \\ \sigma & \text { surface tension, } \mathrm{N} / \mathrm{m}\end{array}$

ICMFHT Keynote 2-12 


$\begin{array}{ll}\text { Subscripts } \\ b u b & \text { bubble } \\ c b & \text { convective boiling } \\ c r i t & \text { critical } \\ H & \text { heated } \\ L & \text { liquid } \\ L V & \text { liquid-vapor } \\ n b & \text { nucleate boiling } \\ p & \text { constant pressure } \\ s a t & \text { saturation } \\ V & \text { vapor }\end{array}$

\section{References}

[1] L. Cheng, E. P. Bandarra Filho, and J. R. Thome, "Nanofluid two-phase flow and thermal physics: A new research frontier of nanotechnology and its challenges," J. Nanosci. Nanotechnol., vol. 8, pp. 3315-3332, 2008.

[2] L. Cheng, and L. Liu, "Boiling and two phase flow phenomena of refrigerant-based nanofluids: Fundamentals, applications and challenges," Int. J. Refrig., vol. 36, pp. 421-446, 2013.

[3] S. K. Das, and S. U. S. Choi, and H. Patel, "Heat Transfer in nanofluids-A review," Heat Transf. Eng., vol. 27, no. 10, pp. 3-19, 2006.

[4] L. Cheng, "Nanofluid heat transfer technologies," Recent Patents Eng., vol. 3, no. 1, pp. 1-7, 2009.

[5] L. Cheng, "Microscale and nanoscale thermal and fluid transport phenomena: Rapidly developing research fields," Int. J. Microscale Nanoscale Thermal Fluid Transport Phenomena, vol., no. 1, pp. 3-6, 2010.

[6] L. Cheng, and G. Xia, "Fundamental issues, mechanisms and models of flow boiling heat transfer in microscale channels," Int. J. Heat Mass Transfer, vol. 108, pp. 97-127, 2017.

[7] L. Cheng, "Flow patterns and bubble growth in microchannels," Microchannel Phase Change Transport Phenomena, pp. 91-140, 2016.

[8] L. Cheng, "Flow boiling heat transfer with models," Microchannel Phase Change Transport Phenomena, pp. 141191, 2016.

[9] L. Cheng, "Fundamental issues of critical heat flux phenomena during flow boiling in microscale-channels and nucleate pool boiling in confined spaces," Heat Transfer Eng., vol. 34, no. 13, pp. 1011-1043, 2013.

[10] L. Cheng, and D. Mewes, "Review of two-phase flow and flow boiling of mixtures in small and mini channels," Int. J. Multiphase Flow, vol. 32, pp. 183-207, 2006.

[11] L. Cheng, and J. R. Thome, "Cooling of microprocessors using flow boiling of $\mathrm{CO}_{2}$ in a micro-evaporator: Preliminary analysis and performance comparison," Appl. Therm. Eng., vol. 29, pp. 2426-2432, 2009.

[12] L. Cheng, "Flow boiling heat transfer and critical heat flux phenomena of nanofluids in microscale channels," Int. $J$. Micoscale Nanoscale Thermal Fluid Transport Phenomena, vol. 5, no. 3\&4, pp. 201-214, 2014.

[13] G. Xia, M. Du, L. Cheng, and W. Wang, "Experimental study on the nucleate boiling heat transfer characteristics of a multi-wall carbon nanotubes water based nanofluid in a confined space," Int. J. Heat Mass Transfer, vol. 113, pp. 59-69, 2017.

[14] J. A. Eastman, S. U. S. Choi, S. Li, W. Yu, and L. J. Thompson, "Anormalously increased effective thermal conductivities of ethylene glycol-based nanofluids containing copper nanoparticles," Appl. Phys. Lett., vol. 78, pp. pp. 718-720, 2001.

[15] S. K. Das, N. Putra, P. Thiesen, and W. Roetzel, "Temperature dependence of thermal conductivity enhancement for nanofluids,” ASME J. Heat Transfer, vol. 125, pp. 567-574, 2003.

[16] M. J. Biercuk, M. C. Llaguno, M. Radosavljevic, J. K. Hyun, and A. T. Johnson, "Carbon nanotube composites for thermal management," Appl. Phys. Lett., vol. 80, pp. 2767-2769, 2002.

[17] S. Berber, Y. K. Kwon, and D. Tomanek, "Unusually high thermal conductivity of carbon nanotubes," Phys. Rev. Lett., vol. 84, pp. 4613-4616, 2000.

[18] S. U. S. Choi, Z. G. Zhang, W. Yu, F. E. Lockwood, and E. A. Grulke, "Anomalous thermal conductivity enhancement in nanotube suspensions," Appl. Phys. Lett., vol. 79, pp. 2252-2254., 2001. 
[19] D. P. Kulkarni, D. K. Das, and S. L. Patil, "Effect of temperature on rheological properties of copper oxide nanoparticles dispersed in propylene glycol and water mixture," J. Nanosci Nanotechnol., vol. 7, pp. 2318-2322, 2007.

[20] D. P. Kulkarni, D. K. Das, and G. A. Chukwu, "Temperature dependent rheological property of copper oxide nanoparticles suspension (nanofluid)," J. Nanoscj. Nanotechnol., vol. 6, pp. 1150-1154, 2006.

[21] C. T. Nguyen, F. Desgranges, N. Galanis, G. Roy, T. Maré, S. Boucher, and H. A. Minsta, "Viscosity data for $\mathrm{Al}_{2} \mathrm{O}_{3}$-water nanofluid-hysteresis: is heat transfer enhancement using nanofluids reliable?," Int. J. Therm. Sci., vol. 47, pp. 103-111, 2008.

[22] Y. Ding, H. Alias, D. Wen, and R. A. Williams, "Heat transfer of aqueous suspensions of carbon nanotubes," Int. J. Heat Mass Transfer, vol. 49, pp. 240-250, 2006.

[23] D. Shin, and D. Banerjee, "Enhanced specific heat of silica nanofluid," ASME J. Heat Transfer, vol. 133, 024510, 2010.

[24] R. S. Vajjha, and D. K. Das, "Specific heat measurement of three nanofluids and development of new correlations," ASME J Heat Transfer, vol. 131, pp. 1-7, 2009.

[25] I. C. Nelson, and D. Banerjee, "Flow loop experiments using polyalphaolefin nanofluids," J. Thermophys. Heat Transfer, vol. 23, pp. 752-761, 2009.

[26] S. Tanvir, S. Jain, and L. Qiao, "Latent heat of vaporization of nanofluids: Measurements and molecular dynamics simulations," J. Appl. Phys., vol., 118, 014902, 2015.

[27] S. Lee, P. E. Phelan, L. Dai, R. Prasher, A. Gunawan, and R. A. Taylor, "Experimental investigation of the latent heat of vaporization in aqueous nanofluids," Appl. Phys. Lett., vol. 104, 151908, 2014.

[28] Y. M. Yang, and J. R. Maa, "Boiling of suspension of solid particles in water," Int. J. Heat Mass Transfer, vol. 27, pp. 145-147, 1984.

[29] M. Chopkar, A. K. Das, I. Manna, and P. K. Das, "Pool boiling heat transfer characteristics of ZrO2-water nanofluids from a flat surface in a pool," Heat Mass Transfer, vol. 44, pp. 999-1004, 2008.

[30] C. Y. Yang, and D. W. Liu, "Effect of nano-particles for pool boiling heat transfer of refrigerant 141B on horizontal tubes," Int. J. Microscale Nanoscale Therm. Fluid Transp. Phenom., vol., no. 3, pp. 233-243, 2010.

[31] L. Cheng, D. Mewes, and A. Luke, "Boiling phenomena with surfactants and polymeric additives: A state-of-the-art review," Int. J. Heat Mass Transfer, vol. 50, pp. 2744-2771, 2007.

[32] S. K. Das, N. Putra, and W. Roetzel, "Pool boiling characteristics of nanofluids on horizontal narrow tubes," Int. J. Multiphase Flow, vol. 29, pp. 1237-1247, 2003.

[33] J. H. Kim, K. H. Kim, and S. M. You, "Pool boiling heat transfer in saturated nanofluids," 2004 -ASME Int. Mech. Eng. Congr. \& Exp., Nov. 13-19, 2004, Anaheim, Californian, USA, Heat Transfer, vol. 2, pp. 621-628.

[34] S. M. You, J. H. Kim, and K. H. Kim, "Effect of nanoparticles on critical heat flux of water in pool boiling heat transfer," Appl. Phys. Lett., vol. 83, pp. 3374-3376, 2003.

[35] S. J. Kim, I. C. Bang, J. Buongiorno, and L.W. Hu, "Surface wettability change during pool boiling of nanofluids and its effect on critical heat flux," Int. J. Heat Mass Transfer, vol. 50, pp. 4105-4116, 2007.

[36] H. Kim, J. Kim, and M. H. Kim, "Effect of nanoparticles on CHF enhancement in pool boiling of nano-fluids," Int. J. Heat Mass Transfer, vol. 49, pp. 5070-5074, 2006.

[37] K. J. Park, D. Jung, and S. E. Shim, "Nucleate boiling heat transfer in aqueous solutions with carbon nanotubes up to critical heat fluxes," Int. J. Multiphase Flow, vol. 35, pp. 525-532, 2009.

[38] H. S. Ahn, N. Sinha, M. Zhang, D. Banerjee, S. Fang, and R. H. Baughman, "Pool boiling experiments on multiwalled carbon nanotube (MWCNT) forests," ASME J. Heat Transfer, vol. 128, pp. 1335-1342, 2006.

[39] S. Ujereh, T. Fisher, and I. Mudawar, "Effects of carbon nanotube arrays on nucleate pool boiling," Int. J. Heat Mass Transfer, vol. 50, pp. 4023-4038, 2007.

[40] H. S. Ahn, N. Sinha, M. Zhang, D. Banerjee, S. Fang, and R. H. Baughman, "Pool boiling experiments on multiwalled carbon nanotube (MWCNT) forests," ASME J. Heat Transfer, vol. 128, pp. 1335-1342, 2006.

[41] S. Khandekar, Y. M. Joshi, and B. Mehta, "Thermal performance of closed two-phase thermosyphon using nanofluids," Int. J. Therm. Sci., vol. 47, pp. 659-667, 2008.

[42] K. Henderson, Y. G. Park, and L. P. Liu, "Flow boiling heat transfer of R-134a-based nanofluids in a horizontal tube,” Int. J. Heat Mass Transfer, vol. 53, pp. 944-951, 2010. 
[43] Z. H. Liu, X. F. Yang, and G. L. Guo, "Effect of nanoparticles in nanofluids on thermal performance in a miniature thermosyphon," J. Appl. Phys., vol. 102, 013526, 2007.

[44] H. B. Ma, S. U. S. Choi, M. Tirumala, C. Wilson, Q. Yu, and K. Park, "An experimental investigation of heat transport capability in a nanofluid oscillating heat pipe," ASME J. Heat Transfer, vol. 128, pp. 1213-1216, 2006.

[45] Z. H. Liu, J. G. Xiong, and R. Bao, "Boiling heat transfer characteristics of nanofluids in a flat heat pipe evaporator with micro-grooved heating surface," Int. J. Multiphase Flow, vol. 33, pp. 1284-1295, 2007.

[46] Z. H. Liu, and Y. H. Qiu, "Boiling heat transfer characteristics of nanofluids jet impingement on a plate surface," Heat Mass Transfer, vol. 43, pp. 699-706, 2007.

[47] Y. Park, A. Sommers, L. Liu, G. Michna, A. Joardar, and A. Jacobi, "Nanoparticles to Enhance Evaporative Heat Transfer," The 22 $2^{\text {nd }}$ Int. Congr. Refrig., Beijing, August 21-26, 2007, paper number: ICR07-B1-309.

[48] M. A. Akhavan-Behabadi, M. Nasr, and S. Baqeri, "Experimental investigation of flow boiling heat transfer of R600a/oil/CuO in a plain horizontal tube," Exp. Therm. Fluid Sci., vol. 58, pp. 105-111, 2014.

[49] V. Nikkhah, M. M. Sarafraz, F. Hormozi, S. M. Peyghambarzadeh, "Particulate fouling of CuO-water nanofluid at isothermal diffusive condition inside the conventional heat exchanger - experimental and modeling," Exp. Therm. Fluid. Sci., vol. 60, pp. 83-95, 2015.

[50] G. Paul, P. K. Das, and I. Manna, "Assessment of the process of boiling heat transfer during rewetting of a vertical tube bottom flooded by alumina nanofluid," Int. J. Heat Mass Transfer, vol. 94, pp. 390-402, 2016.

[51] S. J. Kim, T. McKrell, J. Buongiorno, and L. W. Hu, "Alumina nano-particles enhance the flow boiling critical heat flux of water at low pressure," ASME J. Heat Transfer, vol. 130, 044501, 2008.

[52] S. J. Kim, T. McKrell, J. Buongiorno, and L. W. Hu, "Experimental study of flow critical heat flux in aluminawater, zinc-oxide-water, and diamond-water nanofluids," ASME J. Heat Transfer, vol. 131, 043204, 2009.

[53] H. S. Ahn, H. Kim, H. Jo, S. Kang, W. Chang, and M. H. Kim, "Experimental study of critical heat flux enhancement during forced convective flow boiling of nanofluid on a short heated surface," Int. J. Multiphase Flow, vol. 36, pp. 375-384, 2010.

[54] H. S. Ahn, S. Kang, H. Jo, H. Kim, and M. H. Kim, "Visualization study of the effects of nanoparticles surface deposition on convective flow boiling CHF from a short heated wall," Int. J. Multiphase Flow, vol. 37, pp. 215-228, 2011.

[55] H. S. Ahn, S. H. Kang, and M. H. Kim, "Visualized effect of alumina nanoparticles surface deposition on water flow boiling heat transfer," Exp. Therm. Fluid Sci., vol. 37, pp. 154-163, 2012.

[56] T. I. Kim, W. J. Chang, and S. H. Chang, "An experimental study on CHF enhancement in flow boiling using $\mathrm{Al}_{2} \mathrm{O}_{3}$ nano-fluid," Int. J. Heat Mass Transfer, vol. 53, pp. 1015-1022, 2010.

[57] T. I. Kim, W. J. Chang, and S. H. Chang, "Flow boiling CHF enhancement using $\mathrm{Al}_{2} \mathrm{O}_{3}$ nanofluid and an $\mathrm{Al}_{2} \mathrm{O}_{3}$ nanoparticle deposited tube," Int. J. Heat Mass Transfer, vol. 54, pp. 2021-2025, 2011.

[58] S. W. Lee, S. D. Park, S. Kang, S. M. Kim, H. Seo, D. W. Lee, and I. C. Bang, "Critical heat flux enhancement in flow boiling of $\mathrm{Al}_{2} \mathrm{O}_{3}$ and $\mathrm{SiC}$ nanofluids under low pressure and low flow conditions," Nucl. Eng. Technol., vol. 44, pp. 429-436, 2012.

[59] S. W. Lee, K. M. Kim, and I. C. Bang, "Study on flow boiling critical heat flux enhancement of graphene oxide/water nanofluid," Int. J. Heat Mass Transfer, vol. 65, pp. 348-356, 2013.

[60] H. S. Ahn, and M. H. Kim, "The effect of micro/nanoscale structures on CHF enhancement," Nucl. Eng. Technol., vol. 43, pp. 205-216, 2011.

[61] T. Lee, J. H. Lee, and Y. H. Jeong, "Flow boiling critical heat flux characteristics of magnetic nanofluid at atmospheric pressure and low mass flux conditions," Int. J. Heat Mass Transfer, vol. 56, pp. 101-106, 2013.

[62] H. Aminfar, M. Mohammadpourfard, and R. Maroofiazar, "Experimental study on the effect of magnetic field on critical heat flux of ferrofluid flow boiling in a vertical annulus," Exp. Therm. Fluid Sci., vol. 58, pp. 156-169, 2014.

[63] M. Boudouh, H. L. Gualous, and M. De Labachelerie, "Local convective boiling heat transfer and pressure drop of nanofluid in narrow rectangular channels," Appl. Therm. Eng., vol. 30, pp. 2619-2631, 2010.

[64] J. Lee, and I. Mudawar, "Assessment of the effectiveness of nanofluids for single-phase and two-phase heat transfer in micro-channels," Int. J. Heat Mass Transfer, vol. 50, pp. 452-463, 2007.

[65] A. A. Chehade, H. L. Gualous, S. Le Masson, F. Fardoun, and A. Besq, "Boiling local heat transfer enhancement in minichannels using nanofluids," Nanoscale Res. Lett., vol. 8, pp. 1-20, 2013. 
[66] G. Duursma, K. Sefiane, A. Dehaene, S. Harmand, and Y. Wang, "Flow and heat transfer of single- and two-phase boiling of nanofluids in microchannel," Heat Transf. Eng., vol. 36, no. 14-15, pp. 1252-1265, 2015.

[67] V. Khanikar, I. Mudawar, and T. Fisher, "Effect of carbon nanotube coating on flow boiling in a micro-channel," Int. J. Heat Mass Transfer, vol. 52, pp. 3805-3817, 2009.

[68] S. Vafaei, and D. Wen, "Critical heat flux (CHF) of subcooled flow boiling of alumina nanofluids in a horizontal microchannel," ASME J. Heat Transfer, vol. 132, 102404, 2010.

[69] S. Vafaei, and D. Wen, "Flow boiling heat transfer of alumina nanofluids in single microchannels and the roles of nanoparticles," J. Nanoparticle Res., vol. 13, pp. 1063-1073, 2011.

[70] Z. Edel, and A. Mukherjee, "Flow boiling dynamics of water and nanofluids in a single microchannel at different heat fluxes," ASME J. Heat Transfer, vol. 137, 011501, 2015.

[71] L. Yu, A. Sur, and D. Liu, "Flow boiling heat transfer and two-phase flow instability of nanofluids in a minichannel," ASME J. Heat Transfer, vol. 137, 051502, 2015.

[72] M. G. Cooper, "Saturation nucleate pool boiling - a simple correlation," Int. Chem. Eng. Symp. Ser., vol. 86, pp. 785-792, 1984.

[73] H. K. Forster, and N. Zuber, "Dynamics of vapor bubbles and boiling heat transfer," AIChE J., vol. 1, pp. 531-535, 1955.

[74] K. Stephen, and M. Abdelsalam, "Heat transfer correlation for natural convection boiling," Int. J. Heat Mass Transfer, vol. 23, pp. 73-87, 1980.

[75] J. H. Lienhard, and V. K. Dhir, "Peak pool boiling heat-flux measurements on finite horizontal flat plates," ASME J. Heat Transfer, vol. 95, pp. 477-482, 1973.

[76] N. Kattan, J. R. Thome, and D. Favrat, "Flow boiling in horizontal tubes: Part 3. heat transfer model based on flow pattern," ASME J. Heat Transfer, vol. 120, pp. 156-165, 1998.

[77] L. Wojtan, R. Revellin, and J. R. Thome, "Investigation of critical heat flux in single, uniformly heated microchannels," Exp. Therm. Fluid Sci., vol. 30, pp. 765-774, 2006. 